\title{
Exploring the basis for parents' negative reactions to being informed that their child is overweight
}

\author{
Fiona Gillison ${ }^{1, *}$, Fay Beck ${ }^{1}$ and Joanna Lewitt ${ }^{2}$ \\ ${ }^{1}$ Department for Health, University of Bath, Bath BA2 7AY, UK: ${ }^{2}$ NHS Bath \& North East Somerset, \\ PCT Headquarters, St Martin's Hospital, Bath, UK
}

Submitted 19 April 2013: Final revision received 30 July 2013: Accepted 2 August 2013: First published online 23 September 2013

\begin{abstract}
Objective: Increasing parental awareness of childhood obesity is an important part of tackling the issue. However, parents' negative reactions to being informed that their children are overweight or obese can hinder their engagement with relevant services. The present study aimed to develop a deeper understanding of why parents react negatively, to help commissioners and service providers design services that are more acceptable to them.

Design: Open, qualitative responses to a survey were collected using a postal questionnaire. Responses were analysed using content analysis.

Setting: One local authority in south-west England.

Subjects: The sample frame included all parents receiving letters informing them that their child was overweight (91st-98th centile) or very overweight (98th-100th centile) through the UK National Child Measurement Programme in 2012.

Results: Forty-five of 313 eligible parents (14\%) responded to the survey, of whom forty-three rejected either to the judgement that their child was overweight and/or being provided with this feedback. Primary reasons for objection included: lack of trust in the measures used, lack of belief that being overweight is important for children's health (relative to a healthy lifestyle), and fear that discussing weight with children will trigger eating disorders. In addition, parents' responses suggested that they considered receiving this feedback to be a criticism of their parenting skills.

Conclusions: Overall, three areas for improving communication with parents were suggested: tailoring letters; providing information about the importance of weight independently of lifestyle; and addressing parents' concerns about the risks of talking to children about their weight.
\end{abstract}

Childhood obesity is a significant health concern throughout Europe $^{(1)}$. An important initial step in the process of preventing and tackling childhood obesity is raising awareness among parents that their child is overweight ${ }^{(2,3)}$, as without parental involvement and support, the potential impact of interventions to reduce obesity is limited ${ }^{(4,5)}$. Past work suggests that fewer than half of parents of overweight children correctly recognise their child as such ${ }^{(6)}$, with some studies estimating this to be as low as $30 \%{ }^{(7)}$.

An example of how parental awareness can be raised is provided by the UK National Child Measurement Programme (NCMP), a nationwide school-based monitoring programme introduced in the UK in $2006^{(8)}$. The scheme was introduced as a surveillance programme to provide robust data to monitor national trends in childhood weight on entry to primary school (aged $4-5$ years) and again in Year 6 (aged 10-11 years). The NCMP calculates BMI centiles using the UK 1990 Growth Reference charts, and uses surveillance thresholds (85th and 95th centiles) for national comparison and clinical thresholds (91st and 98th centiles) for individual feedback ${ }^{(9)}$.

As the process identifies children whose weight raises a concern, it is ethical practice to intervene by providing feedback to parents on their child's weight along with an offer of support to those willing to receive it. Given that the provision of tailored information may have greater impact than generic health messages ${ }^{(10)}$, it was anticipated that the programme would also help health professionals to engage with families for whom a child's weight may be an issue. However, this has not always been the case, and one factor that may have limited the effectiveness of the NCMP is the negative reaction that some parents have to receiving the feedback that their child is overweight ${ }^{(11,12)}$.

Negative parental reactions to initiatives that attempt to engage with parents on the issue of childhood obesity 
(e.g. angry phone calls) are not limited to responses to the UK system ${ }^{(13)}$. Negative responses are reported only for a small minority of parents ${ }^{(11-13)}$; however, dealing with them may be distressing for the staff involved and may lead to services ceasing to provide this feedback to parents. For example, in a 2011 survey of over 200 local UK NCMP leads, one-third of staff involved in the provision of feedback did not consider the benefits of providing this information to outweigh its negative impacts $^{(12)}$. However, while telling a parent that their child is overweight may well lead to short-term distress, there is no evidence that it has a negative effect on parents or children over the long term. Conversely, there is evidence that providing feedback about a child's weight can bring positive changes in contributory parental behaviours, such as feeding patterns ${ }^{(11)}$ and engagement in active play ${ }^{(5)}$. As such, it is important that the practice continues.

While the views of health professionals as to the benefits and challenges of providing feedback to parents on a child's weight are well documented ${ }^{(11,12,14)}$, little research is available directly exploring parents' views. Secondary information from school nurses suggests that many parents are concerned that discussing weight with their child will trigger an eating disorder ${ }^{(12)}$, and audits suggest that parents opt out of initiatives to weigh children in school to avoid weight-related teasing ${ }^{(15)}$. Developing a deeper understanding of parents' feelings and perspectives through first-hand accounts is an important step in designing a more acceptable approach to the provision of this feedback and thus one that is more likely to lead to parents' active participation in tackling overweight in childhood $^{(11)}$.

The aim of the present study was to investigate the factors behind parents' negative reactions to receiving information that their child is overweight or very overweight (clinically obese) through the UK NCMP in south-west England during 2012. The objectives were to identify whether parents agreed with the judgements made on their children, what they objected to about the experience of receiving this information, and to explore how the way in which this information is communicated could be improved.

\section{Methods}

\section{Design}

The study adopted a mixed methods design ${ }^{(16)}$. As the purpose of the study was to explore and better understand the perspectives of a subgroup of parents, rather than to record generalisable findings, the primary data were qualitative. However, it was considered useful to explore the prevalence of some key beliefs among the sample (e.g. whether parents accepted that their children were overweight) and conduct comparisons between the responses of parents of overweight $v$. very overweight children. Therefore, a number of quantitative (closed) questions were included to inform the interpretation and context of qualitative findings. This mixed approach stems from a pragmatist research perspective, which is driven by the research question rather than adherence to any particular epistemology standpoint ${ }^{(17)}$.

\section{Recruitment}

The sample frame included all parents whose children were identified as overweight or very overweight (clinically obese) as part of standard NCMP procedures in one NHS (National Health Service) primary care trust in England, during spring and summer of 2012. The population within the catchment area is predominantly white British, living in both rural and urban areas. While levels of deprivation are generally below the national average, there are pockets of deprivation with a small number of neighbourhoods featuring in the most deprived 10\% nationally. The NCMP process involves the school nurse team first contacting parents to inform them that the programme is taking place and providing them with an opportunity to opt out on behalf of their child. Weight and height measurements in light clothing, without shoes, are then collected by school nurses within school for all participating children, and the child's weight and BMI centile relative to children of the same age are reported in a letter to parents. Parents whose children are identified as very overweight (i.e. above the 98th centile) also receive a telephone call from a school nurse prior to receipt of the letter, to provide an opportunity for the result to be discussed in person. The term 'very overweight' is used in place of the medical term 'obese' when communicating this information to parents to reduce potential upset given the stigma associated with obesity. Therefore, for clarity, 'very overweight' will be used in the remainder of the present paper. The letter also provides information on local services and physical activity and dietary initiatives available to support and assist parents in responding to the information.

Approximately two weeks after receiving the NCMP letter, parents were mailed a further letter inviting them to take part in the research study and enclosing an openresponse questionnaire. Responses were returned to an independent research address in a freepost envelope or could be completed online. To encourage open responses, parents were reassured that their feedback would remain anonymous and would directly feed into changes in the service. However, this meant we could not identify non-responders for follow-up. In order to encourage greater participation parents were provided with an incentive in the form of entry into a draw for a $₫ 25$ shopping voucher. The study was conducted according to the guidelines laid down in the Declaration of Helsinki and all procedures involving human subjects/patients were approved by the Department for Health Ethics Committee, University of Bath. 


\section{Questionnaire design}

The survey was designed through collaboration between the lead author, a public health commissioner (third author) and the school nurse team (Appendix). The survey comprised five sections: (i) parents' agreement/disagreement with the assessment of their child's weight status and their previous awareness of this; (ii) parents' planned responses to receiving the letter; (iii) barriers to addressing their child's weight; (iv) ways in which the primary care trust/local authority could help them to make positive changes; and (v) how the process of providing feedback through the NCMP could be improved. The questionnaire comprised a series of closed questions (e.g. 'Do you agree with the assessment that your child is overweight?') followed by an open comment box for eliciting the reasons behind these responses.

\section{Analysis}

Qualitative responses to open questions were analysed using a combination of conventional and summative qualitative content analysis ${ }^{(18)}$. Conventional content analysis is appropriate to answer research questions in which researchers wish to avoid using preconceived categories and which is inductive in nature (i.e. not driven by a large body of existing research or theory $)^{(19)}$. In the present study, two independent researchers familiarised themselves with the response forms of all participants, reviewing all unabridged written comments which they then coded inductively into indicative categories. The codes generated were compared between the two researchers and consolidated into overarching themes. Differences in categorisation/interpretation were resolved through discussion; the aim of this process was not to arrive at a definitive answer, but to ensure that all themes and attributions presented were justified by the data. Summative content analysis ${ }^{(18)}$ was used to enhance understanding of the issues that emerged by: (i) exploring the prevalence of beliefs within the sample to provide a degree of scale for the findings; and (ii) facilitating a comparison of the representation of themes between groups (e.g. overweight $v$. very overweight, agreement $v$. dispute of NCMP judgement).

\section{Results}

In total forty-five responses were received from 313 parents whose children were identified as overweight ( $n$ 128) or very overweight ( $n$ 185) in the target area (a 14\% response rate). Twelve responses were received from parents of very overweight children and thirty-three from parents of overweight children (see Table 1).

Fewer parents of overweight children agreed with the judgement made than parents of very overweight children ( $n 16 v . n 9$ respectively; $48 v .75 \%$ ), although the difference was not significant $\left(\chi^{2}=2 \cdot 36, P=0 \cdot 12\right)$. Reasons commonly cited for this included: believing BMI to be an invalid measure of body fat (particularly for children who had started puberty or who were believed to have a muscular body type); considering that a child did not 'look' visibly overweight (when compared with other children or family members); believing that a judgement could not be made on a single measurement occasion; and believing that lifestyle behaviours (i.e. diet and exercise) should be taken into account (Table 2).

The majority ( $n$ 22, 92\%) of respondents who did accept that their child was overweight felt that the judgement on their child, and the need for health services to get involved, was unwarranted. Quotes illustrating parents' rationales for their position are presented in Table 2. Most consistently, parents appeared to believe that if a child is physically active and eats a healthy diet then there can be little or no independent risk to their health as a result of being overweight. Moreover, there was a tendency for parents to rate their child's health favourably compared with underweight or healthyweight children who had poor diets/physical activity levels. This suggests that parents do not subscribe to health professionals' implied assumption that being overweight is an important health issue in its own right.

Table 1 Summary of quantitative survey responses among parents who received letters informing them that their child was overweight or very overweight through the UK National Child Measurement Programme in one local authority in south-west England, spring/summer 2012

\begin{tabular}{|c|c|c|c|c|c|c|}
\hline & \multicolumn{2}{|c|}{ Overall } & \multicolumn{2}{|c|}{ Overweight } & \multicolumn{2}{|c|}{ Very overweight } \\
\hline & $n$ & $\%$ & $n$ & $\%$ & $n$ & $\%$ \\
\hline Parental agreement with assessment & 24 & 53 & 16 & 48 & 9 & 75 \\
\hline Prior awareness of child's weight status & 22 & 49 & 14 & 42 & 8 & 67 \\
\hline Parents prompted to action & 22 & 49 & 15 & 45 & 7 & 58 \\
\hline \multicolumn{7}{|l|}{ Parental support for different service approaches } \\
\hline One-to-one support & 10 & 22 & 6 & 18 & 4 & 33 \\
\hline Telephone support & 8 & 18 & 6 & 18 & 2 & 17 \\
\hline Internet support & 7 & 16 & 5 & 15 & 2 & 17 \\
\hline Group-based support & 7 & 16 & 3 & 9 & 4 & 33 \\
\hline More physical activity opportunities & 17 & 38 & 13 & 39 & 4 & 33 \\
\hline More healthy eating activities & 12 & 27 & 7 & 21 & 5 & 42 \\
\hline Psychological/emotional support & 11 & 24 & 6 & 18 & 5 & 42 \\
\hline Preference for services to be open to children of all weight categories & 26 & 58 & 18 & 54 & 8 & 67 \\
\hline
\end{tabular}


Table 2 Reasons for lack of parental concern at child's weight status among parents who received letters informing them that their child was overweight or very overweight through the UK National Child Measurement Programme in one local authority in south-west England, spring/summer 2012

\begin{tabular}{|c|c|}
\hline Category & Illustrative quotes \\
\hline \multicolumn{2}{|l|}{ Lack of belief in judgement } \\
\hline \multirow[t]{2}{*}{ Lifestyle not included in assessment } & $\begin{array}{l}\text { 'My child exercises every day of the week with horse riding and running and as you } \\
\text { should know muscle weighs heavier than fat.' }\end{array}$ \\
\hline & $\begin{array}{l}\text { 'You do not take into account any exercise a child does. My child is very tall and } \\
\text { horse rides twice a week and jogs every night.' }\end{array}$ \\
\hline Child is naturally large & $\begin{array}{l}\text { 'If you look at the rest of his activities and family members then his natural weight } \\
\text { and body size is large.' }\end{array}$ \\
\hline \multirow[t]{2}{*}{ Puberty } & $\begin{array}{l}\text { 'My daughter is } 11 \text { years old and going through puberty when girls develop "puppy } \\
\text { fat". She is healthy (eating wise) and active.' }\end{array}$ \\
\hline & $\begin{array}{l}\text { 'She is developing quickly ... therefore on an adult's BMI chart she is in the OK } \\
\text { range, which I feel is more relevant.' }\end{array}$ \\
\hline $\mathrm{BMI}$ is not a valid measure & $\begin{array}{l}\text { 'BMI is not always a fair assessment; it depends on different ethnic groups and } \\
\text { also in muscular people.' } \\
\text { 'BMI is [an] outmoded and blunt instrument.' }\end{array}$ \\
\hline Isolated measurement & $\begin{array}{l}\text { 'If weighed every year and there was a pattern of being overweight then action } \\
\text { should be taken. But I strongly feel that one weight during Year } 6 \text { should not lead } \\
\text { to a child being labelled overweight.' }\end{array}$ \\
\hline Normal relative to peers & 'There are much fatter children out there and my son isn't that bad!' \\
\hline \multicolumn{2}{|l|}{ Belief that the judgement is unwarranted } \\
\hline Risk of harm & $\begin{array}{l}\text { 'By telling children they are overweight you are causing eating disorders with } \\
\text { Year } 6 \text { children where hormones are running riot and they are already very } \\
\text { conscious of their body shapes.' } \\
\text { 'I have not told my son about this letter. I think it could be a damaging "seed" to } \\
\text { plant in any child's head when they consider themselves healthy.' }\end{array}$ \\
\hline Physical activity and lifestyle mitigate risks & $\begin{array}{l}\text { '[My] child [is] at the age where a tiny weight gain is acceptable - as long as [his] } \\
\text { diet [is] under control this will disappear.' }\end{array}$ \\
\hline Child will naturally grow out of being overweight & $\begin{array}{l}\text { 'Often children fill out then suddenly get taller.' } \\
\text { 'He is very short for his age and I feel he will even out as he grows.' }\end{array}$ \\
\hline Lack of belief that weight is a risk to health & $\begin{array}{l}\text { 'I am heartily sick of the body fascism being dished out to children within school. } \\
\text {.. Dieting and this paper is nonsense as you are expecting compliance to get } \\
\text { people to look a certain way or punish them, if they don't.' }\end{array}$ \\
\hline Parental responsibility & $\begin{array}{l}\text { 'When the letter arrives it seems like a bolt out of the blue and that you are being } \\
\text { heavily criticised as an irresponsible parent.' }\end{array}$ \\
\hline
\end{tabular}

\section{Content analysis}

Only two respondents were open to receiving help from the school nurse or NCMP team and considered the process of being informed to have been helpful. The remaining parents did not want external help in reducing their child's weight, for reasons ranging from the belief that no one outside the family could or should help (e.g. 'I realise that healthy eating and awareness of weight issues is a subject that parents should deal with at home, and establish good habits'), through to the belief that any external input represented unwarranted interference (e.g. 'We are helping our daughter develop a healthy attitude to eating and exercise and resent the interference from the Nanny State'). Consistent with this, the majority of parents would not support the introduction of healthservice interventions designed to help them to control their child's weight, and felt that any service introduced specifically to reduce childhood obesity (e.g. extended opportunities for physical activity) should be open to all children, not only those identified as being overweight or very overweight.

Despite not wanting external assistance, all but one parent who agreed that their child was overweight were planning to make changes to their child's lifestyle themselves as a result of receiving the NCMP letter (e.g. encouraging physical activity, reducing portion size). It was notable that not all parents proposed to involve their child in this process; eight of nineteen parents had changed their child's home food or activity environment without making this clear to their child or telling them why.

Excluding children from being involved in lifestyle changes reflected a wider-held concern for many parents that discussing weight with their child would be harmful either to the child's self-esteem or because it risked triggering eating disorders (e.g. 'Discussing this with a 10 -year-old is hard. I fear that by going down the overweight road with children is heading towards the dreaded anorexia/bulimia route'). For these parents, fear of harm was the primary reason why they objected to receiving feedback on their child's weight at all. A number of parents reported that their child had read the letter themselves and that this had been a distressing experience for them (e.g. 'Thanks to your letter my child now thinks she looks disgusting and looks at the calorie content of everything she puts in her mouth'). Parents' responses inferred that they perceived the risk of eating disorders to be far greater 
than the health consequences of being overweight or very overweight. Furthermore, although some parents acknowledged that their children had already suffered bullying or teasing because of their weight, they still avoided actively engaging them in talking about weight or attempting to lose weight for fear of upsetting them further (e.g. 'Slight nervousness about making him too aware of diet etc. - don't want him to be aware he's overweight as already bullied by children'). This provides some indication of the scale of parents' concerns in relation to eating disorders, as it suggests that their fears of the anticipated, but as yet unknown, negative effects of talking about weight with their child outweighed fears of the harm that their child was already experiencing through weight-related bullying and teasing.

Some parents' responses also suggested that they objected to being informed that their child was overweight as they felt this inferred a criticism of their parenting skills. The majority of parents felt that they already knew what a healthy lifestyle should involve and already provided this for their child (e.g. 'I feel this is a very unhelpful exercise... I am not an uneducated person and I know what's good for her'). As such, they interpreted the NCMP letter as feedback that they had failed to effectively act on this knowledge (e.g. 'Reading through the questionnaire, I am again made to feel bad as I have not ticked the boxes to say I am going to put my daughter on a diet. If there was a box to say "Are you going to continue feeding your child a healthy diet and encourage her to exercise?" I would tick that.... Yes, the letter did upset me as I felt judged and unable to reply to anyone as to why I perceive her weight to be where it is'). The degree of anger and defensiveness contained in many responses may therefore reflect parents' responses to a perceived criticism of their parenting, along with disappointment at not living up to their expectations for themselves of being able to manage their child's weight.

Parents were asked for their views of how the NCMP letter could be improved to better communicate this sensitive information to them. Most comments reflected parents' view that they should not have been contacted at all (for the reasons set out in the themes presented to this point), rather than expressing particular disagreement with how the information was communicated. However, a number of constructive suggestions were made, including requests for a better explanation of how to interpret BMI data (e.g. 'I would like to see a weight range of where she would be for her height and age. BMI does not mean a bean to the normal person who stands on the scales at home. Plus it would help us to see where she should be, average weight wise') and a desire for the provision of more individually tailored information (e.g. 'I feel that a "standard" letter is not suitable in all cases mine included. Although sections are applicable it would have been more help to know the level of concern based on her BMI being 1 point over a healthy weight').

\section{Discussion}

The present study sought to explore parents' first-hand accounts of the factors underpinning their negative reactions to being told that their child is overweight. In line with past work ${ }^{(11)}$, our interpretation of the results assumes that parents who were more upset by the receipt of the letter would be more likely to respond. As such the findings are not intended to be representative of all parents with overweight children, but to provide insight into the views of an important and often vocal subgroup of parents for whom the process is particularly distressing or unacceptable.

Two central themes emerged from comments collated in the present study: (i) lack of acceptance of the evidence and (ii) fear that taking action and talking to their child about his/her weight would be harmful. The two themes may not be independent, as some reluctance to accept the evidence may stem from fear that in doing so they would then have a duty to their child to take action, which they did not want or feel able to do. Responding to health promotion initiatives with denial or resistance is common, and is suggested to result from factors such as loss of faith in public services, distrust of health professionals ${ }^{(20)}$, or feeling that there are too many health messages around that are perceived to be 'telling' people what they should or should not do ${ }^{(21)}$. Certainly our findings were consistent with this, in that parents demonstrated a clear lack of trust in school nurses' ability to accurately assess their child's weight status. Denial that a child is overweight may also suggest a response to cognitive dissonance ${ }^{(22)}$. Cognitive dissonance describes the discomfort that people feel when their actions are contradictory to their beliefs (e.g. continuing to overeat when you are aware that it causes you harm). To resolve the dissonance, a person can change his/her behaviour (i.e. eat less) or change his/her attitude or belief (e.g. reject the evidence that being overweight is harmful). In many instances, people are more likely to change their attitude than their behaviour, as it is easier to accomplish. Little or no work has been conducted on the importance of cognitive dissonance in the obesity domain, but further investigation of whether parental rejection of weight messages may be a result of this response may be worthwhile to better understanding of the mechanisms of effects, in order to improve our approach to working with parents.

A further consideration in understanding parents' unwillingness to accept that their child is overweight may relate to a lack of belief in their ability to change it, i.e. their self-efficacy ${ }^{(23)}$. According to social cognitive theory, both a lack of confidence to carry out an action, and a lack of confidence that executing a given action will result in a desired outcome, can undermine motivation ${ }^{(23)}$. In the present study, a number of parents reported having previously tried and failed to bring about change in their 
child's lifestyle or to control their child's weight. These parents commented that they knew what a healthy diet or lifestyle should be and already provided it for their child (although whether parents typically judge this accurately is a subject of debate in the literature $\left.{ }^{(6)}\right)$. As such, it appears that parents had a low expectancy that changes they considered to be at an acceptable level would result in meaningful weight change. This is consistent with the few examples of past work to have measured parents' self-efficacy and outcome expectancies towards influencing their children's diet, which have shown a positive impact of these factors on parent behaviour ${ }^{(24)}$.

Both themes may also reflect a general lack of understanding of the degree of health risk associated with childhood obesity that is independent of lifestyle factors. This finding is consistent with past work in other countries, although published work has largely been reported only for pre-school children ${ }^{(25,26)}$. Parents of overweight children commonly show bias in believing their children to be more active and eating a healthier diet than healthy-weight children $^{(27)}$, and extrapolate from this that paediatric growth charts are not relevant for their child ${ }^{(25,28)}$. Our study $s$ uggests that these beliefs, representing a so-called optimism bias, are retained through to primary school age. However, we note that even within the scientific community, BMI is not universally accepted as a means of establishing health risk in children or adults, so parents' questioning of this metric is entirely reasonable ${ }^{(29)}$.

Parents' fear that addressing weight issues with their child may be harmful is a logical concern and indeed being overweight in childhood is linked to the development of disordered eating patterns ${ }^{(30)}$, which in a small minority of cases can lead to eating disorders ${ }^{(31)}$. These concerns may link to parents' self-efficacy and outcome expectancies, in terms of their having low confidence that they could bring about a positive change in their child's weight while avoiding a psychologically or physically harmful outcome. However, there is no evidence to show that the process of children talking about weight with their parents acts as the trigger for this, rather than, for example, the responses overweight children encounter from others outside the home every day ${ }^{(32,33)}$. Being overweight is associated with poorer well-being indices (e.g. self-concept and body-esteem $)^{(13)}$ regardless of whether it is acknowledged and discussed. Despite a number of parents being aware that their child was being teased or bullied because of his/her weight, it was striking that they showed greater concern for the possible future risk of eating disorder than for how being overweight was currently affecting their child's well-being. While parents may be attempting to protect their child through not discussing the child's weight, other studies show that lack of action still has the potential for harm. For example, increased parental concern about weight status without subsequent action was associated with increased negative self-evaluations in 5-year-old girls, independently of the child's initial weight status ${ }^{(13)}$. Such findings suggest that health professionals should be mindful of the potential negative outcomes for children's health and well-being when raising awareness to parents and should consider how to ensure sufficient steps are taken to mitigate these risks $^{(34)}$

A further factor that may deter parents from believing their child is overweight, and that has been shown to undermine self-efficacy for change, is the stigma associated with obesity ${ }^{(35)}$. While focusing conversations with parents on children's behaviours (i.e. physical activity and healthy eating) rather than weight itself has been forwarded as one means of minimising stigma ${ }^{(15)}$, this is not without challenges; in the present study most parents considered that their child had a healthy diet and was already sufficiently active for health. While previous research suggests that parents' perceptions in this respect are often inaccurate $e^{(6,7)}$, they would be unlikely to be motivated towards change unless these perceptions changed too. One approach to tackling this may be for schools to engage parents and children in monitoring their diet and physical activity levels against recommended standards, in order to provide parents with more objective information with which to make more informed judgements.

Negative outcomes from raising parental awareness are not inevitable, however; past research provides examples of ways in which parents can respond to childhood overweight to reduce weight and enhance well-being. For example, more authoritative parenting styles, in which parents play a guiding role but discuss and explain decision making, has been associated with improved obesity outcomes for adolescents (e.g. lower BMI, increased fruit and vegetable consumption) ${ }^{(36)}$. Conversely, instigating changes in children's lifestyles without their involvement, such as restricting food intake, may be associated with further weight gain rather than weight loss as children commonly react against changes being imposed on them without their involvement (i.e. find ways to eat more) ${ }^{(37)}$. The finding in the present study that $40 \%$ of parents who reported planning to instigate changes to their child's diet proposed to do so without involving their child is therefore of concern. A number of comments indicated that parents' reluctance to discuss or address their child's weight stemmed in part from a lack of confidence that they would be able to make a positive change; these included the difficulty of discussing weight management with young children, motivating children who do not enjoy sport and exercise, and having tried and failed to make changes previously. If information and advice to help parents adopt approaches to help their child manage his/her weight that have been shown to be more effective (in terms of promoting both physical and mental health) could be provided in an acceptable format, this may help to boost confidence and promote better engagement with services or available advice. 


\section{Limitations}

The scope of the present study is limited by its size, as only $14 \%$ of the parents contacted responded to the survey. Due to ethical and data protection considerations participant responses remained anonymous, so we were not able to follow up non-responders. While the sample achieved may well reflect the majority of those who do object strongly to the information received (and thus, the target group of the present study), it is lower than in previous studies ${ }^{(11,12)}$. Therefore we cannot infer that the present findings generalise to other parents within or outside the research locality. Further, we did not record parent characteristics, such as socio-economic, age, ethnicity, lifestyle characteristics and parental styles, so cannot comment on or explore differences between parents from different backgrounds.

Past work confirms that parents' characteristics and parenting styles can influence a child's weight ${ }^{(38,39)}$ and so may logically also help to explain why some parents reject the information that their child is overweight, whereas others find it useful. For example, some of the comments received in the present study confirmed that parents had difficulty in interpreting the BMI data; it is likely that this would be more of an issue for parents who have achieved a lower level of education. Similarly, it would be expected that parents' confidence or willingness to accept that weight is an issue and make changes to their home environment will differ according to family circumstances (e.g. parental weight, family eating/activity habits). Differences in parenting style are already widely recognised as important in determining a range of children's health behaviours; however, while parents and professionals largely agree that many of these (e.g. smoking, unprotected sex and alcohol use) put a child at risk, this shared view cannot be assumed for the behaviours underpinning a child's weight ${ }^{(40,41)}$. Models of parenting suggest that developing a better understanding of the goals parents have in relation to their children is important for health professionals, as failing to appreciate that parents' and health professionals' goals may be very different can result in poor engagement ${ }^{(41)}$. The results of the present study suggest that there is a disconnect between the goals public health workers have for children (i.e. achieving a healthy weight) and parents' goals for their children (e.g. freedom from concern about their weight, avoidance of eating disorders); acknowledging and addressing this difference may provide a useful starting point for more productive discussions. Theories of psychological reactance may also provide a framework for investigating the impact of parenting style on responses to weight-related information. It is proposed that the strength of reactance against health messages stems from the degree of threat a person perceives in that message ${ }^{(42)}$. Linking this to the work on parenting style, it may be that parents who exert greater control over their child's health and behaviour (i.e. adopt an authoritarian parenting style ${ }^{(38)}$ ) feel more threatened by feedback that their child is overweight, as it is more likely to be perceived as a direct criticism of their approach to parenting in this domain and its efficacy. Extending research to explore how individual differences in parent characteristics influence how they respond to health messages about their child's weight in some of the ways discussed here would be useful to help health professionals to better design and target how they communicate with parents.

\section{Conclusions and future directions}

Overall, the findings point to three key aims for promoting more adaptive responses to feedback for parents that their child is overweight. First is to promote parents' confidence and belief in the accuracy and appropriateness of the measurements on which the feedback is based. This could be improved by tailoring letters to account for pubertal development or by providing parents with a means of monitoring their child's growth (e.g. through an online resource). This latter approach would not only provide parents with a sense of control, but also meet their concerns that children are labelled as overweight through a single assessment. Second is to better inform parents of the importance for children of maintaining a healthy weight, independently of a healthy lifestyle. Finally, future work is warranted in reassuring parents that they can talk to their children about managing their weight without risking the development of eating disorders and in exploring how guidance could be developed to help them to do so.

\section{Acknowledgements}

Source of funding: This work was commissioned and funded by NHS Bath and North East Somerset. Members of this organisation provided input into the design of the study, the development of recommendations for practice and drafting of the manuscript. Conflicts of interest: The authors have no conflicts of interest to declare. Authors' contributions: The paper and research design was conceived by J.L. and F.G. Data collection and analysis were conducted by F.B. and F.G. All authors contributed to the writing of the paper. Acknowledgements: The authors are grateful to the Bath and North East Somerset school nurse team for assistance in carrying out this project.

\section{References}

1. Pigeot I, Barba G, Chadjigeorgiou C et al. (2009) Prevalence and determinants of childhood overweight and obesity in European countries: pooled analysis of the existing surveys within the IDEFICS Consortium. Int J Obes (Lond) 33, 1103-1110. 
2. Barlow SE \& Dietz WH (1998) Obesity evaluation and treatment: Expert Committee recommendations. Pediatrics 102, E29.

3. Elder JP, Zyzla GX \& Harris S (1999) Theories and intervention approaches to health-behavior change in primary care. Am J Prev Med 17, 275-284.

4. Daniels SR, Arnett DK, Eckel RH et al. (2005) Overweight in children and adolescents: pathophysiology, consequences, prevention, and treatment. Circulation 111, 1999-2012.

5. Skouteris H, McCabe M, Swinburn B et al. (2011) Parental influence and obesity prevention in pre-schoolers: a systematic review of interventions. Obes Rev 12, 315-328.

6. Parry LL, Netuveli G, Parry G et al. (2008) A systematic review of parental perception of overweight status in children. I Ambul Care Manage 31, 253-268.

7. Jones AR, Parkinson KN, Drewett RF et al. \& Gateshead Millennium Study Core Team (2011) Parental perceptions of weight status in children: the Gateshead Millennium Study. Int J Obes (Lond) 35, 953-962.

8. National Obesity Observatory (2006) National Child Measurement Programme. http://www.noo.org.uk/NCMP (accessed August 2012).

9. Scientific Advisory Committee on Nutrition \& Royal College of Paediatrics and Child Health (2012) Consideration of issues around the use of BMI centile thresholds for defining underweight, overweight and obesity in children aged 2-18 years in the UK. http://www.sacn.gov.uk/pdfs/ sacnrcpch_position_statement_bmi_thresholds.pdf

10. Kreuter MW \& Wray RJ (2003) Tailored and targeted health communication strategies for enhancing information relevance. Am J Health Behav 27, 227-232.

11. Grimmett C, Crocker H, Carnell S et al. (2008) Telling parents their child's weight status: psychological impact of a weight-screening program. Pediatrics 122, e682-e688.

12. Statham J, Mooney A, Boddy J et al. (2011) Taking Stock: A Rapid Review of the National Child Measurement Programme. Report to the Department of Health. London: Thomas Coram Research Unit, Institute of Education, University of London; available at http://eprints.ioe.ac.uk/ 6743/1/Statham2011Taking\%28Report\%29.pdf

13. Davidson KK \& Birch LL (2001) Weight status, parent reaction, and self-concept in five-year-old girls. Pediatrics 107, 46-53.

14. BMRB Social Research (2007) Research into Parental Attitudes Towards the Routine Measurement of Children's Height and Weight. Report Prepared for the Department of Health. London: BMRB Social Research; available at http:// 217.35.77.12/research/england/health/DH_080601.pdf

15. Jain A, Sherman SN, Chamberlin LA et al. (2001) Why don't low-income mothers worry about their preschoolers being overweight? Pediatrics 107, 1138-1146.

16. Johnson RB \& Onwuegbuzie AJ (2004) Mixed methods research: a research paradigm whose time has come. Educ Res 33, 14-26.

17. Denscombe M (2008) Communities of practice: a research paradigm for the mixed method approach. J Mix Methods Res 2, 270-283.

18. Hsiu-Fang Hsieh H \& Shannon SE (2005) Three approaches to qualitative content analysis. Qual Health Res 15, 1277-1288.

19. Kondracki NL \& Wellman NS (2002) Content analysis: review of methods and their applications in nutrition education. I Nutr Educ Behav 34, 224-230.

20. Crossley M (2002) Resistance to health promotion: a preliminary comparative investigation of British and Australian students. Health Educ 102, 289-299.
21. Whitehead D \& Russel G (2004) How effective are health education programmes - resistance, reactance, rationality and risk? Int J Nurs Stud 41, 163-172.

22. Festinger L (1962) A Theory of Cognitive Dissonance. Stanford, CA: Stanford University Press.

23. Bandura A (2001) Social cognitive theory: an agentic perspective. Annu Rev Psychol 52, 1-26.

24. Lohse B \& Cunningham-Sabo L (2012) Eating competence of Hispanic parents is associated with attitudes and behaviors that may mediate fruit and vegetable-related behaviors of 4th grade youth. J Nutr 142, 1903-1909.

25. Genovesi S, Giussani M, Faini A et al. (2005) Maternal perception of excess weight in children: a survey conducted by pediatricians in the province of Milan. Acta Paediatr 94, 747-752.

26. Campbell MW, Williams WC, Hampton A et al. (2006) Maternal concern and perception of overweight in Australian preschool-aged children. Med J Aust 184, 274-277.

27. Goodell LS, Pierce MB, Bravo CM et al. (2008) Parental perceptions of overweight during early childhood. Qual Health Res 18, 1548-1555.

28. Boutelle K, Neumark-Sztainer D, Story M et al. (2002) Weight control behaviors among obese, overweight, and nonoverweight adolescents. J Pediatr Psychol 27, 531-540.

29. Flegal KM \& Ogden CL (2011) Childhood obesity: are we all speaking the same language? Adv Nutr 2, issue 2, 159S-166S.

30. Neumark-Sztainer D (2003) Obesity and eating disorder prevention: an integrated approach? Adolesc Med 14, 159-173.

31. Hayden-Wade HA, Stein RI, Ghaderi A et al. (2005) Prevalence, characteristics, and correlates of teasing experiences among overweight children vs. non-overweight peers. Obes Res 13, 1381-1392.

32. Puhl RM \& Latner JD (2007) Stigma, obesity, and the health of the nation's children. Psychol Bull 133, 557-580.

33. Berge JM, Wall M, Loth $\mathrm{K}$ et al. (2009) Parenting style as a predictor of adolescent weight and weight-related behaviors. $J$ Adolesc Health 46, 331-338.

34. Ikeda JP, Crawford PB \& Woodward-Lopez G (2006) BMI screening in schools: helpful or harmful. Health Educ Res 21, 761-769.

35. Puhl R, Luedicke J \& Peterson JL (2013) Public reactions to obesity-related health campaigns. Am J Prev Med $\mathbf{4 5}$, 36-48.

36. Clark HR, Goyder E, Bissell P et al. (2007) How do parents' child-feeding behaviours influence child weight? Implications for childhood obesity policy. J Public Health 29, 132-141.

37. Golan M \& Crow S (2004) Parents are key players in the prevention and treatment of weight-related problems. Nutr Rev 62, 39-50.

38. Rhee KE, Lumeng JC, Appugliese DP et al. (2006) Parenting styles and overweight status in first grade. Pediatrics 117, 2047-2054.

39. Elva M, Arredondo EM, Elder JP et al. (2006) Is parenting style related to children's healthy eating and physical activity in Latino families? Health Educ Res 21, 862-871.

40. Dempsey AF, Zimet GD, Davis RL et al. (2006) Factors that are associated with parental acceptance of human papillomavirus vaccines: a randomized intervention study of written information about HPV. Pediatrics 117, 1486-1493.

41. Jackson C \& Dickinson DM (2009) Developing parenting programs to prevent child health risk behaviors: a practice model. Health Educ Res 24, 1029-1042.

42. Rains SA (2013) The nature of psychological reactance revisited: a meta-analytic review. Hum Commun Res 39, $47-73$. 
Appendix

\section{National Child Measurement Programme Parent Feedback}

\section{Section 1: Receiving the news that your child is overweight}

1. Did you receive a phone call ahead of the letter from the school nurse?

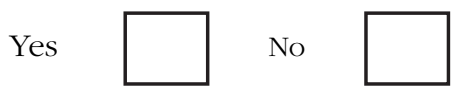

2. If yes, did you find this helpful?

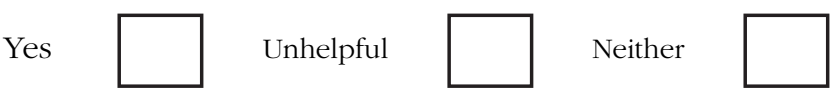

Please comment

3. Do you agree with the assessment that your child is overweight?

Yes

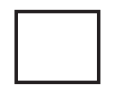

No

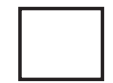

Unsure

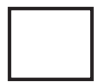

If no, please tell us why:

If $\boldsymbol{y e s}$, were you already aware of this?

Yes

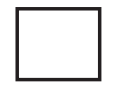

No

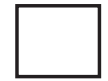

Unsure

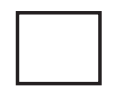

\section{Section 2: What happens next?}

1. Are you planning to make any changes as a result of receiving the letter?

Yes

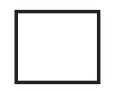

No

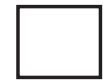

Undecided

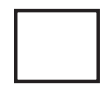

If yes, what are you planning to do?

2. Have you started this already?

Yes

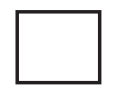

No

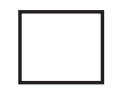


3. Are there any barriers preventing you from making any changes that you might want to make? Yes

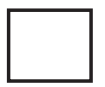
No

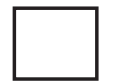

Not planning changes

Are you able to say what these barriers are?

4. What would help you to overcome these barriers?

\section{Section 3: What can we do to help?}

1. If you could design the perfect service to help you improve your family's lifestyle what would it offer? (ideas welcome!)

2. Please tick any of the following elements that you think would be essential

\begin{tabular}{lll} 
One-to-one support & \\
Telephone support & \\
Internet support & \\
Mroup-based support & \\
More physical activity opportunities & \\
More healthy eating activities & \\
\hline
\end{tabular}

3. Do you think this service should be free to all?

Yes

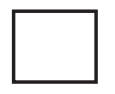

No

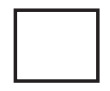




\section{Section 4: General Feedback}

1. If there was one sentence in the letter you would change what would it be, and what would you change it to?

2. Please use the space below to provide any other comments

Thank you for giving us this feedback. 